\title{
Stillbirth surveillance and review in rural districts in Bangladesh
}

\author{
Abdul Halim¹, Mamuda Aminu ${ }^{2 *}$, Juan Emmanuel Dewez ${ }^{2}$, Animesh Biswas ${ }^{1,3}$, A. K. M. Fazlur Rahman ${ }^{1}$ \\ and Nynke van den Broek ${ }^{2}$
}

\begin{abstract}
Background: An estimated 2.6 million stillbirths occur every year, with the majority occurring in low- and middleincome countries. Understanding the cause of and factors associated with stillbirth is important to help inform the design and implementation of interventions aimed at reducing preventable stillbirths.

Methods: Population-based surveillance with identification of all stillbirths that occurred either at home or in a health facility was introduced in four districts in Bangladesh. Verbal autopsy was conducted for every fifth stillbirth using a structured questionnaire. A hierarchical model was used to assign likely cause of stillbirth.

Results: Six thousand three hundred thirty-three stillbirths were identified for which 1327 verbal autopsies were conducted. 63.9\% were intrapartum stillbirths. The population-based stillbirth rate obtained was 20.4 per 1000 births; $53.9 \%$ of all stillbirths occurred at home. $69.6 \%$ of mothers had accessed health care in the period leading up to the stillbirth. $48.1 \%$ had received care from a highly trained healthcare provider. The three most frequent causes of stillbirth were maternal hypertension or eclampsia (15.2\%), antepartum haemorrhage (13.7\%) and maternal infections (8.9\%). Up to $11.3 \%$ of intrapartum stillbirths were caused by hypoxia. However, it was not possible to identify a cause of death with reasonable certainty using information obtained via verbal autopsy in $51.9 \%$ of stillbirths.

Conclusions: Introducing surveillance for stillbirths at community level is possible. However, verbal autopsy yields limited data, and the questionnaire used for this needs to be revised and/or combined with information obtained through case note review.

Most women accessed and received care from a qualified healthcare provider. To reduce the number of preventable stillbirths, the quality of antenatal and intrapartum care needs to be improved.
\end{abstract}

Keywords: Stillbirth, Surveillance, Cause of death, Care seeking, Verbal autopsy, Bangladesh

\section{Background}

Of the estimated 2.6 million stillbirths that occur each year, the majority occur in low- and middle-income countries and at least half of all stillbirths are preventable [1]. However, in most low- and middle-income countries (LMIC), vital registration systems are not in place and the true number of stillbirths that occur is not known. In 2014, the World Health Organization (WHO) and the United Nations Children's Fund (UNICEF) launched the Every Newborn Action Plan (ENAP), a road map to reduce preventable neonatal deaths and

\footnotetext{
* Correspondence: Mamuda.Aminu@lstmed.ac.uk

${ }^{2}$ Centre for Maternal and Newborn Health, Liverpool School for Tropical

Medicine, Pembroke Place, Liverpool L3 5QA, UK

Full list of author information is available at the end of the article
}

stillbirths [2]. One of the recommendations of the ENAP is to improve the recording of every birth, neonatal death, and stillbirth. Improved surveillance should provide contemporaneous data, help to continue to raise awareness and should lead to renewed action and implementation of evidence-based interventions to prevent these deaths wherever possible. ENAP stipulates a target of less than 10 stillbirths per 1000 births by 2035 [2].

Bangladesh is a unique example in terms of health gains despite presenting poorer development indicators than other South Asian countries [3]. Bangladesh showed the fastest annual reduction in stillbirth rates among all countries in South Asia over the 2000-2015 period [1]. Notwithstanding this important reduction, Bangladesh is still ranked seventh globally in terms of

(c) The Author(s). 2018 Open Access This article is distributed under the terms of the Creative Commons Attribution 4.0 International License (http://creativecommons.org/licenses/by/4.0/), which permits unrestricted use, distribution, and reproduction in any medium, provided you give appropriate credit to the original author(s) and the source, provide a link to the Creative Commons license, and indicate if changes were made. The Creative Commons Public Domain Dedication waiver (http://creativecommons.org/publicdomain/zero/1.0/) applies to the data made available in this article, unless otherwise stated. 
absolute number of stillbirths, with an estimated 83,000 stillbirths per annum and a stillbirth rate of 25.4 per 1000 births [4].

Perinatal death surveillance and review is an effective strategy for obtaining data that can be used to improve the quality of care delivered to women and their babies $[5,6]$. Perinatal death reviews help to reduce perinatal morbidity and mortality by providing information on the major causes of, and factors contributing to, stillbirths and neonatal deaths for more targeted and effective action. The cause of most stillbirths in LMIC is never established [7]. A systematic review of the literature highlights the need for more and more accurate data on cause of and factors contributing to stillbirth in LMICs. Most studies are low-quality, hospital-based studies, most of which focused on causes related to maternal diseases, such as hypertensive disorders and infections, and fetal congenital anomalies and do not reflect cause of stillbirth in the general population [8].

The Government of Bangladesh implemented a population-based Maternal and Perinatal Death Review (MPDR) system in four rural districts of the country in 2011. This study was conducted to assess the feasibility of implementing such a population-based surveillance system for stillbirths and to use verbal autopsy to document the cause of and factors contributing to stillbirths occurring either at facility level or in the community.

\section{Methods}

\section{Study area}

The four target districts, Jamalpur, Moulvibazar, Narail and Thakurgaon, comprising a total population of 6.7 million, were targeted based on their relatively poor maternal and neonatal health indicators: uptake of antenatal care (ANC) (63.5\% versus $67.7 \%$ nationally) and percentage of deliveries attended by a skilled provider $(19.9 \%$ versus $31.4 \%$ nationally) [9]. In addition, these districts were the target districts for the joint Government-UN Maternal Newborn Health Initiative which focused on saving maternal and neonatal lives through improved district level planning, investments in infrastructure and supplies and also strengthening of human resources.

\section{Identification of stillbirths}

All grassroot level health and family planning workers, Health Assistants (HA) and Family Welfare Assistants (FWA) (each responsible for a population of 5000-6000) were trained to identify all stillbirths at household level in their area using the following definition of stillbirth: "Birth of a baby after 28 weeks of gestation and who showed no evidence of life, such as beating of the heart, pulsation of the umbilical cord, or definite movement of voluntary muscles, whether or not the umbilical cord has been cut or the placenta is attached, immediately after birth" [10]. This definition also conforms with the WHO definition of stillbirth for international comparison [11].

Trained HAs or FWAs used a network of local community members (teachers, social workers, elected community women members, community health workers, and traditional birth attendants) to obtain information on any stillbirth which occurred in their assigned area. After receiving notification about a stillbirth, the HA/ FWA made a household visit to confirm that the death met the definition criteria. If the definition criteria were fulfilled, the HA/FWA completed a stillbirth notification slip. The slips were sent to an assigned focal person at each upazila (sub-district administrative centre) within 7 to 15 days after the death.

\section{Verbal autopsy}

An expert, multi-disciplinary team under the guidance of the Directorate General of Health Services and the Directorate General of Family Planning (DGFP) developed a verbal autopsy (VA) questionnaire based on recommended WHO VA tools and the existing neonatal death audit forms already available in Bangladesh [12, 13]. The questionnaire was adapted for use by district healthcare workers and family planning workers and translated into Bangla (Additional file 1). The VA questionnaire was then field tested in one district before use in all four study districts. The VA questionnaire included 29 close-ended questions with different response categories including questions on sociodemographic characteristics of the mother, complications during pregnancy and childbirth, access to antenatal care, mode of delivery, healthcare seeking behaviour at the time of antepartum or intrapartum complications, and characteristics of the stillbirth.

To assess if a stillbirth was fresh (likely intrapartum death) or macerated (likely antepartum death), questions around the appearance at birth and whether or not mothers had felt the baby move were included in the VA questionnaire.

Field level supervisors of HAs and FWAs (i.e. Health Inspectors (HI), Assistant Health Inspectors (AHI), and Family Planning Inspectors (FPI)) who oversee a population of 25,000-30,000, received training on the use of the VA questionnaire, facilitated by a team of trained social scientists and medical doctors. Each supervisor conducted at least five VA under supervision to ensure competency in using the tool.

Upon receipt of a death notification, a trained field level supervisor was assigned to conduct a VA at household level of every fifth stillbirth (identified sequentially) which occurred in his/her assigned area. Each VA interview had to include three respondents including the 
mother, father or relatives who were present at the time of the stillbirth (Fig. 1).

\section{Data analysis}

Sociodemographic characteristics of the stillbirths and mothers as well as the circumstances around the death were described using frequencies and proportions.

\section{Assigning cause of death}

An expert panel was created, comprising of an obstetrician, a physician experienced in stillbirth classifications and a paediatrician, to develop a hierarchical model to assign cause of stillbirth. The model was based on information obtained from a systematic literature review to determine cause of and factors associated with stillbirth in LMIC [8]. We considered all causes with characteristics which could potentially be identified using verbal autopsy (VA). Causes with the strongest available evidence to support the diagnosis were ranked first. Eight causes of stillbirth were identified: eclampsia, hypertension, antepartum haemorrhage, diabetes, infection, intrapartum-related hypoxia, external trauma, and ruptured uterus. A category "unknown" was used for any case where there was insufficient or no information to be able to assign a cause of death.

We developed computer-based algorithms containing the specified characteristics of each condition to assign cause of stillbirth for each identified case of stillbirth for which verbal autopsy was conducted. Criteria for diagnosis were developed and agreed with input from all

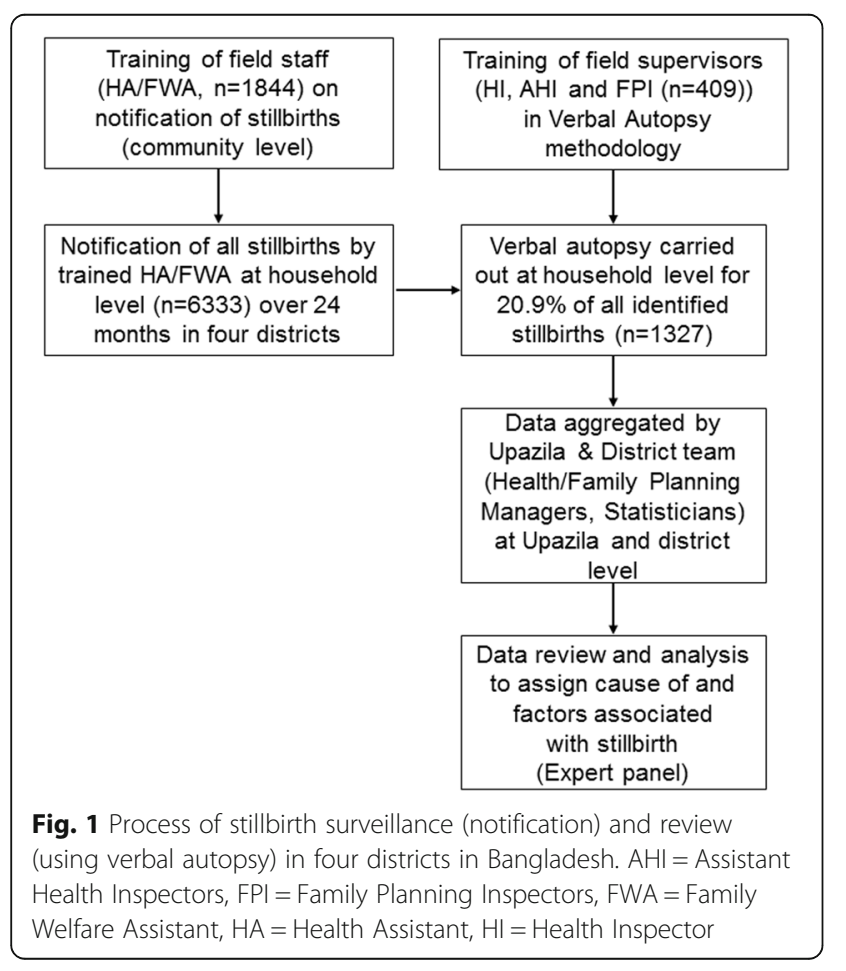

researchers, following a hierarchical model (Additional file 2). For each diagnosis, we considered how likely it is for the diagnosis to be accurate using data obtained via verbal autopsy only. For example, a history of hypertension with convulsion is more likely to be an accurate indication of eclampsia than a history of fever and jaundice for the diagnosis of infection. The algorithm was applied independently by two researchers to all cases of stillbirth initially, and then to fresh and macerated stillbirths separately. There were no discrepancies in results obtained between the two researchers.

\section{Ethical approval}

Ethical clearance was obtained from the Ethical Review Committee (ERC/CIPRB/2010/01) of the Centre for Injury Prevention and Research Bangladesh. The protocol and tools were reviewed and approved for implementation by the Directorate General of Health Services of Bangladesh. Informed, written consent was requested and obtained from each respondent before each verbal autopsy interview. Anonymity and confidentiality was maintained throughout the process. Participation was voluntary.

\section{Results \\ Stillbirth rate}

A total of 6333 stillbirths were identified between January 2011 and December 2012 in the study area, 3025 in year 1 and 3308 in year 2. A total of 1327 VA (20.9\% of all stillbirths reported) were performed.

Using the 2011 crude birth rate of Bangladesh of 22.6 livebirths per 1000 population [13], we estimated a total of 151,420 live births in the study area per year giving an estimated stillbirth rate of 19.6 and 21.4 per 1000 births in 2011 and 2012, respectively.

\section{Maternal characteristics (Table 1)}

The majority of the VA conducted (65\%) included the mothers of the babies who had been stillborn. The mean (SD) age of the mothers was $23.7( \pm 5.7)$ years. Most of the mothers $(1032,77.7 \%)$ had at least completed primary education and 283 (21.3\%) had completed secondary education or above.

Five hundred sixty-eight $(42.8 \%)$ of mothers were primiparous. The majority $(802,60.4 \%)$ reported delivery of a term stillbirth, while $421(31.7 \%)$ reported a preterm delivery and $104(7.8 \%)$ a post-term.

\section{Pregnancy and delivery characteristics}

Most mothers (1059, 79.8\%) attended ANC at least once during the index pregnancy and $449(33.8 \%)$ attended four or more times (Table 1). Almost 6 in 10 (57.3\%) had received care from a skilled healthcare provider (a doctor, a nurse / midwife or a medical assistant). 
Table 1 Characteristics and sociodemographic information of women who experienced a stillbirth $(n=1327)$

\begin{tabular}{|c|c|c|}
\hline \multicolumn{3}{|l|}{ Characteristics } \\
\hline Age categories (years) & $n$ & $\%$ \\
\hline $15-19^{a}$ & 310 & 23 \\
\hline $20-24$ & 491 & 37 \\
\hline $25-29$ & 284 & 21 \\
\hline $30-34$ & 147 & 11 \\
\hline 35 and above & 95 & 7.2 \\
\hline \multicolumn{3}{|l|}{ Education level } \\
\hline No schooling received & 26 & 2.0 \\
\hline Primary incomplete & 269 & 20 \\
\hline Primary complete & 228 & 17 \\
\hline Secondary incomplete & 478 & 36 \\
\hline Secondary or higher & 283 & 21 \\
\hline Do not know & 43 & 3.2 \\
\hline \multicolumn{3}{|l|}{ Parity } \\
\hline 1 & 568 & 42 \\
\hline 2 to 4 & 648 & 48 \\
\hline 5 or more & 111 & 8.4 \\
\hline \multicolumn{3}{|l|}{ Reported pregnancy duration (months) } \\
\hline $7-8$ & 421 & 31 \\
\hline 9 & 802 & 60 \\
\hline$>9$ & 104 & 7.8 \\
\hline \multicolumn{3}{|l|}{ Antenatal care during pregnancy } \\
\hline Any ANC & 1059 & 79 \\
\hline Four or more ANC visits & 449 & 33 \\
\hline $\begin{array}{l}\text { ANC provided by skilled provider (Doctor, Medical } \\
\text { Assistant, Nurse-midwife) }\end{array}$ & 761 & 57 \\
\hline \multicolumn{3}{|l|}{ Reported complications during pregnancy or delivery } \\
\hline Complication during pregnancy & 1041 & 78 \\
\hline Complication during delivery & 865 & 65 \\
\hline \multicolumn{3}{|l|}{ Mode of delivery } \\
\hline Normal Vaginal delivery & 1147 & 86 \\
\hline Assisted vaginal delivery (ventouse or foreps) & 33 & 2.5 \\
\hline Caesarean section & 142 & 10 \\
\hline \multicolumn{3}{|l|}{ Place of delivery } \\
\hline At home & 715 & 53 \\
\hline En route to a health facility & 33 & 2. \\
\hline At a health facility & 579 & 43 \\
\hline \multicolumn{3}{|l|}{ Birth attendant at delivery } \\
\hline $\begin{array}{l}\text { Skilled birth attendant (Doctor, Medical Assistant, } \\
\text { Nurse-midwife) }\end{array}$ & 614 & 46 \\
\hline Unskilled attendant/family member/untrained TBA) & 713 & 53 \\
\hline
\end{tabular}

More than half of all stillbirths (715 (53.9\%)) were born at home or at the house of a traditional birth attendant. Most of the mothers had a normal vaginal delivery $(1147,86.4 \%)$. Overall, $10.7 \%$ of stillbirths were delivered by Caesarean section and $2.5 \%$ by assisted vaginal delivery (vacuum or forceps) or were a breech delivery. $614(46.3 \%)$ of the deliveries were assisted by skilled healthcare providers.

\section{Complications during pregnancy and delivery}

During VA, 1041 (78.4\%) of the mothers reported at least one type of complication during pregnancy (antepartum) and $865(65.2 \%)$ reported at least one type of complication at time of birth (Table 2).

Only $11 \%$ of women had not recognised nor reported a complication during pregnancy or at the time of birth. This was similar for both antepartum and intrapartum.

\section{Care seeking for antepartum complications}

Among the 1041 mothers who experienced an antepartum complication, 725 (69.6\%) had sought care. Among them, $438(60.4 \%)$ accessed care at a health facility. The healthcare facility was a secondary or tertiary level of care in 310 (42.6\%) of the cases (Fig. 2).

Table 2 Complications during pregnancy and childbirth as reported by mothers who had experienced a stillbirth $(n=1041)$

Antepartum Complications $\quad$ Frequency $(n=865) \quad \%$

Hypertension

$202 \quad 19.4$

Facial or limb oedema

384

36.9

Blurred vision

435

41.8

Convulsions (eclampsia or epilepsy)

137

13.2

Unconsciousness

148

14.2

Antepartum Haemorrhage

21.4

High fever

223

470

45.1

Diabetes

101

9.7

Anaemia

414

39.8

Jaundice

9.5

Other complication (not specified)

99

28.2

Intrapartum Complications

294

$\%$

PROM - Premature rupture of membranes 454 Long labour (> 12 h) $\quad 477 \quad 55.1$

Obstructed labour $\quad 315$

Mal-presentation $\quad 166 \quad 19.2$

Convulsions (eclampsia or epilepsy) $\quad 100 \quad 11.6$

Haemorrhage $262 \quad 30.3$

Retained placenta $\quad 100 \quad 11.6$

\begin{tabular}{lll} 
Others (unspecified) & 136 & 15.7 \\
\hline
\end{tabular} 


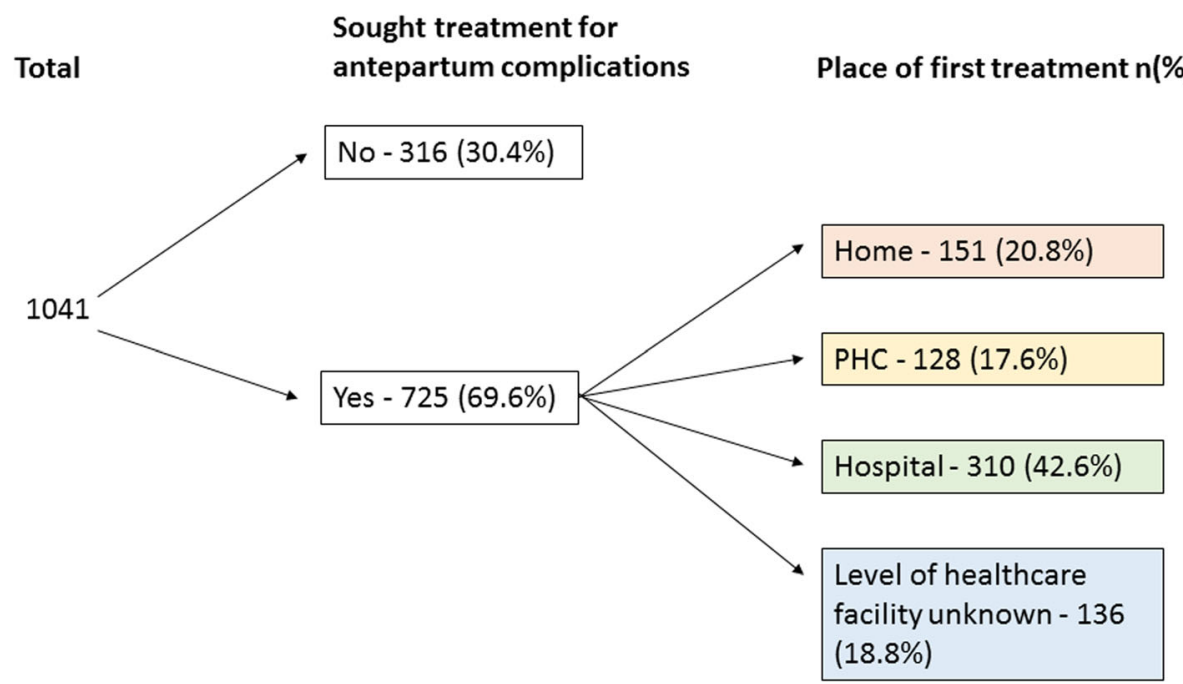

Fig. 2 Care seeking pattern for women who had a recognised complication during pregnancy $(n=1041)$. PHC = Primary Healthcare Centre

Among the 725 women who sought care for antepartum complications, $349(48.1 \%)$ received care from a medical doctor trained in identifying and treating most antenatal complications.

\section{Characteristics of stillbirths}

The sex of the stillborn babies was known in 928 (69.9\%) of the cases. Of these, 534 (57.5\%) were males. A total of $272(20.5 \%)$ were described by mothers as "smaller than normal at birth".

At the time of verbal autopsy, 848 (63.9\%) of the stillbirths were reported to be fresh stillbirths and 464 (34.9\%) macerated at time of birth. However, when considering stricter criteria (including only those who had reported fetal movement at onset of labour and were considered to look like fresh stillbirths), only 491 cases
(58.3\%) could be reported as intrapartum stillbirths and $351(41.7 \%)$ as antepartum stillbirths.

\section{Likely cause of stillbirth}

Of the 1327 cases of stillbirth, 66 (5\%) were due to eclampsia, $136(10.2 \%)$ to hypertension, $182(13.7 \%)$ to antepartum haemorrhage, $41(3.1 \%)$ to diabetes, 115 $(8.7 \%)$ to infections, $96(7.2 \%)$ to intrapartum-related hypoxia (only those without antepartum haemorrhage, hypertension or eclampsia identified - the hierarchical model), and $3(0.2 \%)$ due to external trauma. No cases of ruptured uterus were reported. No cause could be assigned in 688 (51.9\%) of the cases (Table 3; Additional file 3). There was no significant difference between the distribution of likely cause of death for fresh compared to macerated stillbirths ( $p$

Table 3 Likely cause of stillbirth as assigned by expert panel using hierarchical model

\begin{tabular}{llll}
\hline Likely Cause of Stillbirth & $\begin{array}{l}\text { Type of Stillbirth } \\
\text { Fresh Stillbirth } \\
\mathrm{n}(\%)\end{array}$ & $\begin{array}{l}\text { Mll Stillbirths } \\
\text { Combined } \\
\mathrm{n}(\%)\end{array}$ \\
\hline Eclampsia & $39(4.6)$ & $27(5.8)$ & $66(5.0)$ \\
Hypertension & $87(10.3)$ & $44(9.5)$ & $136(10.2)$ \\
Antepartum Haemorrhage & $113(13.3)$ & $69(14.9)$ & $182(13.7)$ \\
Diabetes & $20(2.4)$ & $21(4.5)$ & $31(3.1)$ \\
Maternal Infection & $77(9.1)$ & $38(8.2)$ & $115(8.7)$ \\
Intrapartum-related hypoxia & $96(11.3)$ & $0(0.0)$ & $96(7.2)$ \\
Trauma & $2(0.2)$ & $1(0.2)$ & $3(0.2)$ \\
Unknown & $414(48.8)$ & $264(56.9)$ & $688(51.9)$ \\
Total & $848(100.0)$ & $464(100.0)$ & $1327^{\mathrm{a}}(100.0)$ \\
\hline
\end{tabular}

${ }^{a}$ Total includes 15 stillbirths for which it was not possible to assess if it was a fresh or macerated stillbirth 
$=0.444$ ), after accounting for intrapartum-related hypoxia, which may not be a cause of death in macerated stillbirths.

\section{Discussion}

\section{Main findings}

To the best of our knowledge, this is one of the largest studies to implement a stillbirth surveillance and review programme at population level in a low- or middle-income country. This study shows that district level surveillance of all stillbirths can be introduced successfully and provide a population-based, contemporaneous stillbirth rate using verbal autopsy. This can provide information on type of stillbirth (ante or intrapartum) and on likely cause of, and factors contributing to, stillbirth.

Community-based surveillance was implemented successfully in four districts in Bangladesh where $53.9 \%$ of identified stillbirths occurred at home. Two thirds of all mothers had accessed care during pregnancy for complications recognised by them (or their family) to require health care. Two thirds of these attended a healthcare facility and half of the mothers reported that they had received care from a highly trained healthcare provider.

Antepartum haemorrhage and hypertension or eclampsia were identified as the commonest causes of stillbirth accounting for almost $30 \%$ of stillbirths. Maternal infections were the third most common cause of stillbirth and identified in almost $10 \%$ of cases. However, using information obtained via verbal autopsy, did not allow the identification of a clear cause of death in half of all stillbirths. About two thirds of the cases $(63.9 \%)$ were intrapartum stillbirths. There were no substantial differences in cause of stillbirth between fresh (intrapartum) and macerated stillbirths (antepartum death) except for intrapartum-related hypoxia which was present in at least $11.3 \%$ of stillbirths.

\section{Stillbirth rate}

The stillbirth rate (SBR) obtained was 20.4 per 1000 births. The neonatal mortality rate (NMR) in the study area during the same period was 24.4 per 1000 live births [14]. Bangladesh does not have a system for vital registration data, but in this study, specific effort was made to identify stillbirths. As a proxy, we estimated the SBR/NMR ratio, which was 0.84 . This is in line with high-resource settings with better civil registration systems and vital statistics. The median ratio of SBR to NMR in high income countries is 0.9 (IQR: 0.65-1.15) [4]. This may indicate that the majority of stillbirths in this study population were identified with the introduction of the population-based stillbirth surveillance.

\section{Cause of death}

Findings should be interpreted in light of some limitations. Firstly, as cause of death was assigned hierarchically, the proportion for each cause of death could potentially change as the hierarchy changes. Secondly, verbal autopsy was used to develop a 'clinical history' for each case. A limitation of this is that additional clinical information that could have aided diagnosis of cause of death, including results of laboratory tests, was not available. Thus, this study allowed for the estimation of likely cause of stillbirths for those who died either at facility level or in the community in only about half of the cases (51.9\%). Assigning cause of death from information obtained via verbal autopsy is known to be difficult. Studies from Bangladesh, Pakistan, Tanzania, and Ghana have reported an undetermined cause of stillbirth in 18 to $58 \%$ of cases [7, 15-19].

Furthermore, the maternal infection category does not provide information on type of infection and whether potentially preventable (such as HIV, malaria, syphilis or tuberculosis). The questionnaire used during verbal autopsy in Bangladesh also did not include questions to ascertain whether stillborn babies were identified to have had a congenital anomaly. This is because most congenital anomalies causing death are cardiovascular and chromosomal anomalies and most often cannot be detected by parents in the community [20]. In an earlier systematic review identifying causes of and contributing factors to stillbirth in low- and middle-income countries [8], the main causes of stillbirth (ordered by frequency of reporting) were maternal factors, congenital anomalies, placental causes, asphyxia, umbilical problems, and uterine factors. However, most of the studies included in the review were hospital-based, making the comparison with the results of this study difficult.

Nevertheless, in a similar study using verbal autopsy in India, Aggarwal et al. reported causes of stillbirth to include hypertension (30\%), antepartum haemorrhage (16\%), underlying maternal illness (12\%), congenital malformations (12\%) and obstetric complications (unspecified) (10\%) [21]. However, in their study, stillbirths were defined as death from 24 weeks gestation and this could have explained some of the differences in cause of death observed, particularly with regard to congenital anomalies.

Baqui et al. and Nahar et al. in Bangladesh, as well as Jehan et al. in Pakistan, similarly found that maternal haemorrhage was one of the main causes of stillbirth [7, $15,16]$. Hypertensive disorders as a major cause of stillbirth was reported by Edmond et al. in Ghana $[18,19]$. In Tanzania, Hinderaker et al. found that around $42 \%$ of mothers had an infection, which is four times higher than our results [17]. However, they targeted only rural communities and had a relatively small sample of 60 stillbirths compared to the sample size in this study.

To increase the proportion of cases for which a cause of death can be determined, and with a greater level of certainty, analysis of hospital records, 
diagnoses and management pathways would be needed. However, this would only be feasible in cases where women have been admitted to a healthcare facility and/or for whom good patient-records are available for review.

\section{Hierarchical model for cause of death}

The variability in causes of stillbirth among studies is probably due to the use of different hierarchical models in studies [7, 18]. The proportion of any cause is dependent on the proportion of other causes and if the hierarchy of causes changes, the relative importance of any cause varies in relation to the others. In earlier studies, two different hierarchical models were applied to antepartum and intrapartum stillbirths, whereas we applied a unique model to all stillbirths. In addition, different definitions of each potential cause of stillbirth were used. For example, Hinderaker et al. defined maternal infection as "all kinds of infections" [17]; whereas, the definition used in this study was "the presence of fever and jaundice or fever and premature rupture of membranes". In addition, the prevalence of malaria, the main cause of infection in the study conducted by Hinderaker et al., was higher than in our setting.

\section{Time of death}

In terms of the proportion of ante- and intrapartum stillbirths, our finding, that the proportion of intrapartum stillbirths is higher, is in line with studies conducted in Bangladesh and Pakistan [15, 16, 22, 23]. However, Baqui et al. as well as Edmond et al. found that antepartum stillbirths represent two thirds of all stillbirths [7, $18,19]$. Intrapartum-related hypoxia was estimated to be the cause of stillbirth in 23 to $25 \%$ of cases $[15,16]$, which is substantially higher than the $11 \%$ we found. Another study [7], which had a lower rate of intrapartum stillbirths (37.9\%), assigned intrapartum-related hypoxia as the cause of stillbirth in $20.5 \%$ of stillbirth cases.

However, half of global stillbirths occur at intrapartum period [1]. The differences observed between studies may be because, in LMIC, differentiation of antepartum and intrapartum stillbirths relies mainly on the physical appearance (fresh/macerated classification) of the stillborn, which is often not a reliable way of determining time of death. Besides it has been previously noted that healthcare providers' assessment of physical appearance at time of stillbirth may, in fact, be an unreliable method for assessing time of death [24].

\section{Care-seeking behaviour}

Regarding care seeking for antepartum complications, we found similar results to the study conducted by Skider et al. in a rural district of Bangladesh [25]. In both studies, more than two thirds of women had accessed and received care from a trained healthcare provider. However, the proportion of women receiving care by a trained healthcare provider was lower than in our study (30\% versus $48 \%)$.

\section{Conclusion}

Surveillance of stillbirths at community level is possible. However, using verbal autopsy to explore cause of and factors associated with stillbirth provides limited information on cause of death. It is important that if verbal autopsy is used, it should be complemented by healthcare record and case note review to establish cause of death more accurately, identify substandard care and formulate recommendations to improve quality of care and reduce preventable stillbirths.

For cases where a clear cause of death was identified, most of the causes of stillbirth were preventable. Moreover, most women had sought and received care from a qualified healthcare provider. This suggests that health care during pregnancy and around the time of birth was not optimal in most of these cases. In order to reduce the number of preventable stillbirths, more effort is needed to improve the quality of antenatal and intrapartum care.

\section{Additional files}

Additional file 1: Questionnaire and Consent Form. (PDF 625 kb)

Additional file 2: Hierarchical model and criteria used to assign likely cause of stillbirth using information obtained via verbal autopsy. PROM= Premature rupture of membranes. (TIF $76 \mathrm{~kb}$ )

Additional file 3: Frequency of ante and intrapartum complications among mothers who experienced a stillbirth for all stillbirths combined, fresh stillbirths and macerated stillbirths $(n=1041)$. (TIF $95 \mathrm{~kb}$ )

\section{Abbreviations}

AHI: Assistant Health Inspectors; ANC: Antenatal Care; DGFP: Directorate General of Family Planning; ENAP: Every Newborn Action Plan; FPI: Family Planning Inspectors; FWA: Family Welfare Assistants; HA: Health Assistants: HI: Health Inspectors; LMIC: Low- and middle-income countries; MPDR: Maternal and Perinatal Death Review; SBR: Stillbirth Rate; UNICEF: United Nations Children's Fund; VA: Verbal Autopsy; WHO: World Health Organization

Acknowledgements

We are grateful to Caroline Hercod for editing the manuscript.

Funding

UNICEF Bangladesh; Contract references: PCA-UNICEF/PCA/2012/009 and PCA-NICEF/PCA/2011/003.

Availability of data and materials

The datasets used and/or analysed during the current study are available from the corresponding author on reasonable request.

\section{Author contributions}

MA, JED and NvdB conceptualised the paper and designed the study; $A B$, $A H$ FR contributed to the study design; $A B, A H$, FR assisted with data collection; MA, JED and NvdB analysed the data; AH, MA, JED and NvdB 
wrote the initial draft. All authors contributed to, and approved the final version.

\section{Ethics approval and consent to participate}

Ethical clearance was obtained from the Ethical Review Committee (ERC/ CIPRB/2010/01) of the Centre for Injury Prevention and Research Bangladesh. The protocol and tools were reviewed and approved for implementation by the Directorate General of Health Services of Bangladesh. Informed, written consent was obtained from each respondent before each verbal autopsy interview. In a few cases where participants were under the age of 16, consent was also obtained from their relatives, usually their parents; all interviews were conducted in the presence of at least two other matured adults. Anonymity and confidentiality was maintained throughout the process. Participation was voluntary.

\section{Competing interests}

The authors declare that they have no competing interests.

\section{Publisher's Note}

Springer Nature remains neutral with regard to jurisdictional claims in published maps and institutional affiliations.

\section{Author details}

'Centre for Injury Prevention and Research Bangladesh (CIPRB), Dhaka, Bangladesh. ${ }^{2}$ Centre for Maternal and Newborn Health, Liverpool School for Tropical Medicine, Pembroke Place, Liverpool L3 5QA, UK. ${ }^{3}$ Örebro University, Örebro, Sweden

Received: 10 May 2017 Accepted: 29 May 2018

Published online: 13 June 2018

\section{References}

1. Lawn JE, Blencowe H, Waiswa P, Amouzou A, Mathers C, Hogan D, et al. Stillbirths: rates, risk factors, and acceleration towards 2030. Lancet. 2016; 387:587-603. https://doi.org/10.1016/S0140-6736(15)00837-5.

2. WHO. Every Newborn Action Plan, An Action Plan to End Preventable Deaths. Geneva: World Health Organization, 2014. Available: https://www. everynewborn.org/Documents/Every_Newborn_Action_Plan-EXECUTIVE_ SUMMARY-ENGLISH_updated_July2014.pdf

3. Chowdhury AM, Bhuiya A, Chowdhury ME, Rasheed S, Hussain Z, Chen LC. The Bangladesh paradox: exceptional health achievement despite economic poverty. Lancet. 2013;382:1734-45. https://doi.org/10.1016/S01406736(13)62148-0

4. Blencowe $H_{\text {, Cousens } ~}$, Jassir FB, Say L, Chou D, Mathers C, et al. National, regional, and worldwide estimates of stillbirth rates in 2015, with trends from 2000: a systematic analysis. Lancet Global Health. 2016;4:e98-e108. https://doi.org/10.1016/S2214-109X(15)00275-2.

5. Buchmann EJ. Towards greater effectiveness of perinatal death audit in lowand middle-income countries. BJOG. 2014;121:S134-6.

6. Pattinson R, Kerber K, Waiswa P, Day LT, Mussell F, et al. Perinatal mortality audit: counting, accountability, and overcoming challenges in scaling up in low- and middle-income countries. Int J Gynecol Obstet. 2009;107:S113-22.

7. Baqui AH, Choi Y, Williams EK, Arifeen SE, Mannan I, Darmstadt GL, et al. Levels, timing, and etiology of stillbirths in Sylhet district of Bangladesh. BMC Pregnancy and Childbirth. 2011;11:25. https://doi.org/10.1186/1471 2393-11-25.

8. Aminu M, Unkels R, Mdegela M, et al. Causes of and factors associated with stillbirth in low- and middle-income countries: a systematic literature review. BJOG. 2014:121:141-53. https://doi.org/10.1111/1471-0528.12995.

9. Ministry of Health and Family Welfare. Chapter 3: Accelerating progress towards maternal and neonatal mortality and morbidity reduction project. In: Ministry of Health and Family Welfare, ed. Baseline Survey Report2008. Dhaka, Bangladesh: MoHFW Bangladesh; 2008. pp. 32-40.

10. National Institute of Population Research and Training (NIPORT), Mitra and Associates, Macro International. Bangladesh Demographic and Health Survey 2007 Calverton, MD: Macro International; 2009. Available from: http:// www.dghs.gov.bd/licts_file/images/BDHS/BDHS_2007.pdf

11. WHO. Making Every Baby Count Audit and review of stillbirths and neonatal deaths. Geneva: World Health Organization; 2016. Available: http://www. who.int/maternal_child_adolescent/documents/stillbirth-neonatal-deathreview/en/
12. WHO. Beyond the Numbers: Reviewing maternal deaths and complications to make pregnancy safer. Geneva: World Health Organization; 2004. Available: http://whqlibdoc.who.int/publications/2004/9241591838.pdf

13. National Institute of Population Research and Training (NIPORT), MEASURE Evaluation, International Centre for Diarrhoeal Disease Research, Bangladesh (icddr,b). Bangladesh Maternal Mortality and Health Care Survey 2010. Dhaka, Bangladesh: NIPORT, MEASURE Evaluation, and icddr,b, 2012. Available: http://www.cpc.unc.edu/measure/resources/publications/tr-12-87

14. Halim A, Dewez JM, Biswas A, Rahman F, White S, van den Broek N Neonatal death surveillance and review; causes of neonatal death and determinants of care seeking in Bangladesh. PLoS One. 2016;11:e0159388. https://doi.org/10.1371/journal.pone.0159388.

15. Nahar S, Rahman A, Nasreen HE. Factors influencing stillbirth in Bangladesh: a case-control study. Paediatr Perinat Epidemiol. 2013;27:158-64. https://doi. org/10.1111/ppe.12026.

16. Jehan I, McClure EM, Salat S, Rizvi S, Pasha O, Harris H, et al. Stillbirths in an urban community in Pakistan. Am J Obstet Gynecol. 2007;197:257.e1-8.

17. Hinderaker SG, Olsen BE, Bergsjø PB, Gasheka P, Lie RT, Havnen J, et al. Avoidable stillbirths and neonatal deaths in rural Tanzania. BJOG. 2003;110: 616-23.

18. Edmond KM, Quigley MA, Zandoh C, Danso S, Hurt C, Owusu Agyei S, et al. Aetiology of stillbirths and neonatal deaths in rural Ghana: implications for health programming in developing countries. Paediatr Perinat Epidemiol. 2008a;22:430-7. https://doi.org/10.1111/j.1365-3016.2008.00961.x.

19. Edmond KM, Quigley MA, Zandoh C, Danso S, Hurt C, Owusu Agyei S, et al. Diagnostic accuracy of verbal autopsies in ascertaining the causes of stillbirths and neonatal deaths in rural Ghana. Paediatr Perinat Epidemiol. 2008b;22:417-29. https://doi.org/10.1111/j.1365-3016.2008.00962.x.

20. Flenady V, Middleton P, Smith GC, Duke W, Erwich JJ, Khong TY, et al. Stillbirths: the way forward in high-income countries. Lancet. 2011;377: 1703-17.

21. Aggarwal AK, Jain V, Kumar R. Validity of verbal autopsy for ascertaining the causes of stillbirth. Bull World Health Organ. 2011;89:31-40. https://doi.org/ 10.2471/BLT.10.076828.

22. Ellis M, Azad K, Banerjee B, Shaha SK, Prost A, Rego AR, et al. Intrapartumrelated stillbirths and neonatal deaths in rural Bangladesh: a prospective, community-based cohort study. Pediatrics. 2011;127:e1182. https://doi.org/ 10.1542/peds.2010-0842

23. Owais A, Faruque ASG, Das SK, Ahmed S, Rahman S, et al. Maternal and antenatal risk factors for stillbirths and neonatal mortality in rural Bangladesh: a case-control study. PLoS One. 2013;8:e80164. https:/doi.org/ 10.1371/journal.pone.0080164.

24. Gold KJ, AbdulMumin AS, Boggsa ME, Opare-Addo HS, Lieberman RW. Assessment of "fresh" versus "macerated" as accurate markers of time since intrauterine fetal demise in low-income countries. Int J Gynecol Obstet. 2014:125:223-7.

25. Sikder SS, Labrique AB, Shamim AA, Ali H, Mehra S, Wu L, et al. Risk factors for reported obstetric complications and near misses in rural Northwest Bangladesh: analysis from a prospective cohort study. BMC Pregn Childb 2014; 14:1-13. doi: https://doi.org/10.1186/1471-2393-14-347.

\section{Ready to submit your research? Choose BMC and benefit from:}

- fast, convenient online submission

- thorough peer review by experienced researchers in your field

- rapid publication on acceptance

- support for research data, including large and complex data types

- gold Open Access which fosters wider collaboration and increased citations

- maximum visibility for your research: over $100 \mathrm{M}$ website views per year

At BMC, research is always in progress.

Learn more biomedcentral.com/submissions 